\title{
MOVIMENTOS SOCIAIS E CONFRONTO POLÍTICO: APONTAMENTOS SOBRE O Pensamento de Sidney TarRow
}

\author{
Diego Matheus Oliveira de MENEZES
}

\begin{abstract}
RESUMO: Este ensaio se propõe a discutir os principais pressupostos do pensamento de Sidney Tarrow, bem como sua consequente contribuição para o campo o qual se insere a partir de três elementos centrais a) movimentos sociais como expressão do confronto político b) surgimento dos movimentos sociais; c) dinâmica e elementos da luta política. Nesse sentido, o enfoque do autor na dimensão política e nos fluxos e refluxos do confronto político possibilitou o desenvolvimento de um campo que aborda os movimentos sociais como invenções históricas resultantes da dinâmica do confronto político, se distanciando de abordagens conceituais sistêmicas.
\end{abstract}

PALAVRAS-CHAVE: Movimentos sociais. Sidney Tarrow. Confronto político.

\section{Introdução}

Nas últimas décadas, um vigoroso campo de estudos sobre os movimentos sociais se consolidou nas ciências sociais estimulando uma investigação detalhada sobre o objeto em questão. Decerto, a novidade do surgimento desse novo fenômeno e a velocidade da ampliação de sua atuação contribuíram, a partir da década de 1970, para a referida ebulição de estudos sobre a temática. Todavia, em consequência da diversidade de linhas analíticas e pressupostos não se configura como um campo unificado, mas sim a partir de escolas que mobilizam referências variadas.

* UFBA - Universidade Federal da Bahia. Faculdade de Filosofia e Ciências Humanas. Programa de Pós-Graduação em Ciências Sociais. Salvador - BA - Brasil.40210-730 - ego.matheus@gmail.com. https://orcid.org/0000-0001-5010-0147. 
Em meados da década de 1980, duas correntes despontaram como hegemônicas na área, refletindo a influência das teorias sociais as quais se relacionavam. Aplicando a teoria da escolha racional no intuito de calcular os custos e benefícios da mobilização predominava nos Estados Unidos a Teoria da Mobilização de Recursos (TMR), enquanto na Europa, tratando os movimentos sociais a partir do processo de construção de novas identidades coletivas prevalecia o que se convencionou chamar de Teoria dos Novos Movimentos Sociais (TNMS). Nesse contexto surge o trabalho de Sidney Tarrow, um interessante autor que contribuiu para sistematizar uma série de pressupostos que possibilitaram a construção de um outro caminho possível para as análises sobre os movimentos sociais.

Sidney Tarrow, sociólogo americano, a partir de obras seminais como O Poder em Movimento: Movimentos Sociais e confronto político (2009), Dynamics of contention em parceria com Doug McAdam e Charles Tilly (2005) e Contentious politics em parceria com Charles Tilly (2007), foi um dos principais autores da Teoria do Processo Político (TPP). Teoria esta que inova ao correlacionar os estudos sobre os movimentos sociais com a investigação sobre o confronto político, ressaltando suas dimensões políticas e culturais.

Alguns conceitos são essenciais para a compreensão do trabalho de Sidney Tarrow. Em seu pensamento destaca-se a ênfase na dinâmica da luta política, a qual a partir do seu fluxo e refluxo proporciona o surgimento de diversas formas de confronto político (TARROW, 2009, McADAM; TARROW; TILLY, 2009). O autor traça uma cuidadosa análise sobre os movimentos sociais manejando conceitos como estrutura de oportunidades políticas, repertórios de confronto, ciclos de confronto e quadros interpretativos.

Tendo em vista o intuito desse ensaio de apresentar os principais pressupostos do pensamento tarrowniano, bem como sua consequente contribuição para o campo no qual se insere, irei nos tópicos a seguir abordar os conceitos em questão a partir de três elementos centrais do trabalho do autor: a) Movimentos sociais como expressão do confronto político b) surgimento dos movimentos sociais; c) dinâmica e elementos da luta política.

Por fim, discutirei duas de suas contribuições com consequências metodológicas de destacado impacto nos estudos sobre movimentos sociais: a) enfoque na dimensão política e nos fluxos e refluxos do confronto político; b) movimentos sociais como invenções históricas resultantes da dinâmica do confronto político.

\section{Movimentos sociais como expressão do confronto político}

$\mathrm{Na}$ fundação do pensamento tarrowiano apresenta-se a ideia do movimento social como invenção histórica diretamente relacionada com o confronto político. 
Nesse sentido, a discussão sobre os movimentos sociais se insere em uma teoria mais ampla sobre o confronto, segundo a qual, a partir da Idade Moderna, ocorrem alterações significativas nas configurações da luta política. Os movimentos sociais, portanto, ocupam um momento específico de uma longa e diversa trajetória de conflito, surgindo como fenômeno essencial para a compreensão do confronto político contemporâneo. Nas palavras do autor:

(...) afirmo que o confronto político é desencadeado quando oportunidades e restrições políticas em mudança criam incentivos para atores sociais que não tês recursos próprios. Eles agem através de repertórios de confronto conhecidos, expandindo-os ao criar inovações marginais. O confronto político conduz a uma interação sustentada com opositores quando é apoiado por densas redes sociais e estimulado por símbolos culturalmente vibrantes e orientados para a ação. $\mathrm{O}$ resultado é o movimento social (TARROW, 2009, p.18).

Em suma, Tarrow em diálogo com as contribuições de Charles Tilly, apresenta os movimentos sociais como uma forma histórica de expressão de reivindicações (ALONSO; COSTA; MACIEL, 2007) que surgiu no ocidente a partir do século XVIII a partir de mudanças nas redes sociais, na organização do estado nacional e na própria dinâmica da luta política. Definidos pelo autor como "desafios coletivos baseados em objetivos comuns e solidariedade social numa interação sustentada com as elites, opositores e autoridades" (TARROW, 2009, p.21), em sua base fundante estaria o que o autor denomina de ação coletiva de confronto.

$\mathrm{O}$ ato irredutível que está na base de todos os movimentos sociais, protestos e revoluções é a ação coletiva de confronto. A ação coletiva pode assumir muitas formas - breve ou sustentada, institucionalizada ou disruptiva, monótona ou dramática. A maioria delas ocorre no interior de instituições, através de grupos constituídos que agem em nome de objetivos que dificilmente causariam estranheza. (TARROW, 2009, p.19).

A ação coletiva torna-se de confronto quando pessoas sem acesso suficiente às instituições agem em prol de exigências ainda não atendidas, desafiando as autoridades. Tarrow (2009) argumenta nessa perspectiva, que o confronto pode ocorrer de diversas formas transformando-se lentamente ao longo do tempo, sendo o fio de convergência entre movimentos sociais, protestos e revoluções. Nesse sentido, os movimentos se circunscrevem em uma forma específica de confronto político que surge em determinado tempo histórico, onde densas redes sociais possibilitam a manutenção de uma contenda política por tempo razoável. Portanto, um episódio de confronto só se transforma em um movimento social quando a ação coletiva é sustentada. 
Não obstante, além da já referida capacidade de interação sustentada, o autor apresenta mais três outras propriedades empíricas dos movimentos sociais: protesto coletivo, objetivo comum e solidariedade social. A primeira delas, se relaciona com a capacidade de criar desafios contenciosos e disruptivos, possibilitando os movimentos se tornarem atrativos para apoiadores, enquanto ganham atenção de opositores e possíveis eleitores a serem por eles representados (TARROW, 2009).

Sua segunda propriedade empírica se refere à necessidade de organização de reivindicações comuns aos opositores e autoridades para que pessoas participem de uma causa (TARROW, 2009). Sem propósitos, valores e interesses comuns indivíduos não terão incentivos para se filiarem aos movimentos, impossibilitando a existências dos mesmos. Objetivos bem definidos, portanto, proporcionam incentivos valiosos para estimular possíveis insurgentes, construindo um arcabouço compartilhado entre os membros. Contudo, esses interesses coletivos precisam ser reconhecidos por seus participantes a partir de sentimentos de identidade. Por esse motivo, a terceira característica dos movimentos sociais é a solidariedade social, a qual se refere à capacidade dos membros se reconhecerem como integrantes de uma mesma comunidade.

Torna-se importante ressaltar que o autor, ao definir os movimentos sociais a partir das suas quatro características empíricas evita deliberadamente adotar um conceito analítico baseado em símbolos conceituais exteriores a realidade. Abordaremos com maior cuidado essa questão posteriormente, contudo, por hora é pertinente afirmar que, na perspectiva de Tarrow (2009) os movimentos sociais, como desafios coletivos que surgiram em nosso tempo, existem como formas de ação coletiva de confronto tendo a solidariedade social, os objetivos comuns, os protestos coletivos e a interação sustentada como propriedades observáveis.

Nesse sentido, para compreender o surgimento desse fenômeno é necessário se debruçar sobre a própria trajetória do confronto político. Para isso o autor apresenta uma interessante discussão sobre ação coletiva e repertórios que debateremos a seguir.

\section{Ação coletiva modular e surgimento dos movimentos sociais}

No que se refere ao surgimento dos movimentos sociais, Tarrow (2009) argumenta que a partir do século XVII manifesta-se o que ele denomina de ação coletiva modular. Para melhor entendimento desse processo é relevante nos atermos ao diálogo que o autor trava com Charles Tilly (TILLY; TARROW, 2007) em torno do conceito de repertórios de confronto.

Tilly (GIUGNI; McADAM; TILLY, 1998, p.41), estabeleceu o conceito de repertórios definindo-o como "um conjunto limitado de rotinas que são aprendidas, 
compartilhadas e executadas através de um processo relativamente deliberado de escolha". São, portanto, construções culturais aprendidas a partir da luta política entre opositores e autoridades, onde as pessoas, limitadas pelas opções disponíveis de interação, tentam novas táticas vantajosas, na margem de práticas bem estabelecidas (TARROW, 2009).

A ideia chave, portanto, é que a ação em uma luta política ocorre a partir de rotinas aprendidas ao longo do tempo em um contexto de interação, formando assim os repertórios de confronto. As pessoas utilizam determinada rotina (protestos, ocupações, greves, etc.) porque sabem como praticá-las, gerando reações das autoridades que buscam neutralizá-las. Da mesma forma, os insurgentes buscam reagir às respostas das autoridades, aprimorando ou criando novas rotinas. Nesse processo relacional o repertório é lentamente renovado em um processo contínuo.

Segundo Tilly (1995) haveria dois tipos de repertórios: o repertório de confronto tradicional e os repertórios de confronto modular. O primeiro tipo, predominante até meados do século XVII, tinha como características ser estreito, bifurcado e particular. Segundo o autor, poderia ser definido por estreito tendo em vista que os interesses em disputa se concentravam predominantemente a uma comunidade específica, enquanto suas rotinas de ação eram particulares por variarem dependendo dos grupos, localidades e questão. Nesse sentido, no repertório tradicional, os modos de confrontar as autoridades só tinham sentido em contextos específicos. Além disso, era bifurcado, pois as pessoas adotavam a ação direta quando tratavam de objetivos locais, enquanto em questões e objetivos nacionais expressavam suas reivindicações às autoridades locais.

A partir da idade moderna, os repertórios de confronto tradicional foram progressivamente substituídos por um novo repertório modular que detinha como principais características a capacidade de ser cosmopolita, modular e autônomo. Por ser modular tem a capacidade de se adaptar facilmente de uma situação para outra, podendo ser utilizado em uma grande variedade de contextos. Além disso, por ser cosmopolita está relacionado com interesses e questões referentes a inúmeras localidades e por ser autônomo mantem contato direto com os núcleos de poder (TILLY, 1995).

A substituição dos repertórios, entretanto, não foi automática. Os novos repertórios foram sendo construídos processualmente, enquanto as rotinas tradicionais foram perdendo espaço. Segundo Tarrow (2009):

O novo repertório não aparecia já pronto e nem as antigas formas de ação coletiva desapareceram de vez. Os triunfos mais visíveis das novas formas apareceram quando as demonstrações, as greves os comícios, as reuniões públicas e as formas similares de interação passaram a prevalecer (TARROW, 2009, p.52). 
Nessa perspectiva a ação coletiva modular é caracterizada pelo predomínio do repertório de confronto modular. Com a combinação de rotinas-chave adaptadas para contextos diversos, campanhas de ação coletiva são construídas, possibilitando que uma grande diversidade de pessoas agisse conjuntamente. Nas palavras do autor:

(...) desenvolveu-se um novo repertório que era cosmopolita em vez de provinciano; autônomo em vez de dependente de rituais herdados ou de ocasiões específicas; e modular em vez de particular. Concentrando-se em algumas poucas rotinas-chave de confronto, ele poderia ser adaptado a um número de ambientes diferentes e seus elementos combinados em campanhas de ação coletiva. O resultado era possibilitar que até mesmo grupos espalhados de pessoas que não se conheciam agissem conjuntamente em desafios sustentados a autoridades e criassem o movimento social moderno (TARROW, 2009, p.59).

Esse contexto ocorre em diálogo com mudanças vigorosas nas sociedades ocidentais da época, sobretudo a consolidação do Estado Nação. Segundo o autor, "ao fazerem guerras, abastecerem cidades e aumentarem impostos, assim como ao construir estradas e regular associações" os Estados tornaram-se "ao mesmo tempo um alvo de reivindicações e um lugar onde se podia realizar disputas com grupos reivindicadores" (TARROW, 2009, p.95). A empreitada por padronização e unificação almejada pelos Estados em expansão e a existência de um objetivo comum aos insurgentes de diversas localidades, criou oportunidades decisivas que estimularam a ampliação do confronto, rompendo assim, as fronteiras locais e territoriais.

\section{Dinâmica e elementos da luta política}

Como abordado anteriormente, a interação entre desafiantes e autoridades, em uma dinâmica de aprendizado onde os participantes buscam se posicionar da melhor forma possível, dá o tom da dinâmica da luta política. Nesse processo relacional, a participação no confronto é incentivada a partir das estruturas de oportunidades e restrições oriundas do contexto. Segundo o autor, estrutura de oportunidades políticas "são dimensões consistentes do contexto político que podem encorajar ou desencorajar pessoas de participarem em ações coletivas" (TARROW, 2009, p.18).

É importante ressaltar que o autor se refere tanto às características estáveis do contexto político quanto a aspectos situacionais. Nesse sentido, as características do Estado, da sociedade e a própria cultura política proporcionam restrições e oportunidade além de estimular ou limitar o acesso a determinados recursos. Esses elementos estáveis influenciam ou constrangem determinadas formas de atuação e 
impactam nas possibilidades dos desafiantes. Contudo, alguns elementos situacionais podem promover mudanças nesses elementos estáveis que podem gerar novas oportunidades aos opositores. A dimensão situacional, portanto, é capturada pelo autor a partir da noção de mudanças na oportunidade. Estas ocorrem a partir de mudanças relevantes no contexto político que compensam, mesmo que por tempo limitado, "as fraquezas em recursos culturais, ideológicos e organizacionais" (TARROW, 2009, p.107). Haveria, segundo o autor, cinco recorrentes momentos de mudanças nas oportunidades políticas, podendo estes ocorrerem combinados ou isoladamente, em uma dinâmica nem sempre visível para todos os atores envolvidos no confronto. Seriam estes: a) ampliando o acesso, b) mudança nos alinhamentos c) elites divididas d) aliados influentes e) repressão e facilitação.

A ampliação no acesso a canais democráticos, como por exemplo, as eleições, surge como aspecto importante para a mudanças nas oportunidades. Conforme Tarrow (2009, p.107), "quanto mais estreitos os caminhos já existentes para a participação, mais provável se torna que cada nova abertura produza novas oportunidades de confronto". A abertura política, portanto, possibilita transformações nas oportunidades e restrições, proporcionando a desafiantes, novas possibilidades de atuação, baixando provisoriamente os custos da atuação política. Por sua vez, mudanças nos alinhamentos políticos criam incertezas que podem ser exploradas por opositores. A instabilidade, portanto, aparece como uma fonte relevante de estímulo ao confronto.

A divisão das elites também é definida como aspecto gerador de mudanças na medida em que proporciona recursos para desafiantes. Tarrow (2009) defende que fissuras e conflitos entre elites tanto incentivam os opositores a se lançarem em confrontos políticos, aproveitando a destabilização das elites vigentes, quanto estimulam segmentos das elites a disputarem o poder.

Outro elemento listado pelo autor está relacionado com o acesso a aliados influentes. Isso ocorre porque aliados com acesso ao sistema funcionam como um valioso recurso externo com o potencial de garantir menor repressão ou maiores garantias para a ação coletiva (TARROW, 2009). Além deste, ele também pontua que a repressão ou facilitação podem estimular o confronto, seja com formas mais brandas ou mais disruptivas. Algumas ações dos detentores do poder podem aumentar ou reduzir os custos para a ação coletiva, produzindo oportunidades ou restrições.

Esses cinco momentos para a mudança nas oportunidades só podem ser mobilizados, contudo, a partir da análise dos aspectos mais estáveis de uma determinada sociedade. Por serem empiricamente orientados, variam com o contexto e com as características do Estado e da sociedade em questão. Além disso, novas observações podem encontrar outros aspectos recorrentes ampliando o conhecimento sobre a estrutura de oportunidades políticas. É exatamente esse caráter dinâmico do conceito que possibilita o auxílio à compreensão das mais diversas conjunturas. A 
listagem feita pelo autor serve mais como um instrumento que orienta a observação das transformações na estrutura de oportunidades do que como categoria engessada. O principal argumento do autor, portanto, se relaciona com a ideia de que ao analisar as mudanças que proporcionam transformações nas oportunidades e restrições à luz das características estáveis dos Estados e das culturas políticas, é possível compreender o surgimento e desenvolvimento das contendas políticas.

Nessa perspectiva, "mudanças nas oportunidades e nas restrições políticas criam os incentivos mais importantes para iniciar novas fases de confronto" (TARROW, 2009, p.24). A ampliação das oportunidades possibilita que pessoas comuns desafiem autoridades ao desvelar a suscetibilidade e fragilidade de um sistema político. Os choques iniciais entre os primeiros ativistas e o Estado, por testarem os limites do controle exercido pelas autoridades, pode explicitar os pontos débeis e incapacidades de lidar com os manifestantes, estimulando atores até então imóveis a tomar parte na contenda e assim criar novas oportunidades que incentivam outros grupos a se organizarem, difundindo o confronto em ciclos.

É através das oportunidades políticas aproveitadas e criadas pelos desafiantes, movimentos e seus aliados e inimigos que começam os grandes ciclos de confronto. Estes, por sua vez, criam oportunidades para as elites e contraelites e as ações que começam nas ruas são resolvidas nos salões de governos ou pelas - e particularmente as ondas de movimentos que são as principais catalisadoras da mudança social - são parte das lutas nacionais de poder. (TARROW 2009, p.45).

No entendimento do autor, um ciclo de confronto seria uma fase acentuada de conflito onde a ação coletiva difunde-se de forma acelerada de grupos mais mobilizados para grupos menos mobilizados, em um ritmo intenso de fluxos de informação e com rápida inovação das formas de confronto. (TARROW, 2009). Sua dinâmica, determinada pela interação entre organizações, movimentos, manifestantes, autoridades, membros de partidos, entre outros, forja alianças e revela inimigos. Assim, as ações tomadas afetam e estimulam novas ações, criando incertezas e novas oportunidades em um processo onde os atores não têm controle sobre os resultados a serem obtidos. Por isso, as oportunidades criadas em um ciclo de confronto podem tanto estimular a organização de novos movimentos sociais, quanto proporcionar incentivos para elites e forças governamentais.

Tarrow (2009), todavia, adverte que as oportunidades só são aproveitadas a partir da coordenação da ação coletiva proporcionada pela confiança e cooperação por meio de enquadramentos interpretativos. Em diálogo com Snow e Benford (1992), pontua que enquadramentos interpretativos são entendimentos e identidades compartilhadas entre os participantes que possibilitam a justificação e mobilização da ação coletiva ao enquadrar descontentamentos dispersos em reivindicações 
amplas. Assim, identidades coletivas são moldadas e imaginários sobre aliados e inimigos são construídos, definindo os parâmetros para identificar o nós e o eles em uma estrutura de conflito (TARROW, 2009). Nessa perspectiva, os quadros interpretativos possibilitam a simplificando e codificação do mundo lá fora em símbolos manejáveis (SNOW e BERNFORD, 1992).

Os símbolos culturais só têm o seu potencial mobilizador aproveitado quando agentes concretos os transformam em quadros interpretativos de confronto. Entretanto, para tal, os símbolos precisam ser alinhados e transformados por líderes que orientarão "os quadros interpretativos de seus movimentos para a ação coletiva em contextos particulares e os amoldam à intersecção entre um alvo da cultura da população e seus próprios valores e objetivos" (TARROW, 2009, p.144).

\section{Contribuições para o campo de estudo sobre os movimentos sociais e consequências metodológicas}

O pensamento construído por Sidney Tarrow logra em contribuir com um campo inovador, tendo em vista que os seus principais pressupostos se distanciam dos estudos sobre movimentos sociais até então predominantes. Neste tópico aprofundarei a análise em dois elementos centrais e de suas consequências metodológicas para o campo de estudos sobre movimentos sociais. Argumento aqui, que no trabalho do autor ocorre um duplo distanciamento da teoria social e política até então hegemônica, ao se afastar tanto do utilitarismo presente nas investigações sobre ação coletiva norte-americanas, quanto da teoria sistêmica predominante em alguns estudos europeus que tratam movimentos sociais como um sistema de ação. Contudo, antes de adentrar nos distanciamentos e rupturas mencionados cabe uma breve contextualização acerca da inserção do autor na clássica discussão sobre estratégia $\mathrm{X}$ identidade que marcou os estudos sobre movimentos sociais.

Ao longo das últimas décadas, não somente foram construídas formas diversificadas de analisar os movimentos sociais, como estas foram colocadas à prova em um longo embate sobre suas discordâncias e diferentes delimitações sobre o campo em questão. Essa contenda dentro do âmbito acadêmico foi sintetizada a partir das noções de identidade e estratégia. Diversos autores argumentam que a principal contribuição da teoria do processo político estaria sobretudo no âmbito da estratégia, enquanto a teoria dos novos movimentos sociais contribui para as noções sobre identidade (ALONSO, 2009).

A teoria dos novos movimentos sociais, apesar de grande diversidade interna, tem grande importância ao se debruçar no processo de formação de identidades coletivas que desafiam as formas consolidadas de se pensar, viver e agir, atuando na própria sociedade em prol de mudanças sociais. Alonso (2009) em um pertinente 


\section{Diego Matheus Oliveira de Menezes}

trecho sobre os três principais teóricos (Touraine, Habermas e Melucci) da TNMS aponta:

Touraine, Habermas e Melucci têm teorias particulares, mas confluem para o mesmo postulado central, o da especificidade dos movimentos sociais da segunda metade do século XX. Para todos, uma mudança macrossocial teria gerado uma nova forma de dominação, eminentemente cultural (por meio da tecnologia e da ciência) e borrado as distinções entre público e privado, acarretando mudanças nas subjetividades e uma nova zona de conflito. As reivindicações teriam se deslocado dos itens redistributivos, do mundo do trabalho, para a vida cotidiana, demandando a democratização de suas estruturas e afirmando novas identidades e valores. Estaria em curso uma politização da vida privada. Os movimentos de classe dariam lugar, assim, a novos movimentos expressivos, simbólicos, identitários, caso do feminismo, do pacifismo, do ambientalismo, do movimento estudantil. (ALONSO, 2009, p. 6).

Em contrapartida, a Teoria do Processo Político (TPP), a partir de autores como Sidney Tarrow, tem relevante importância para se pensar a dimensão da estratégia. A dinâmica que possibilita mudanças no ambiente político é extensamente estudada possibilitando a compreensão sobre o processo relacional de interação estratégica entre atores e o processo de surgimento de movimentos sociais, revoluções, dentre outras formas de ação coletiva. Contribuições, como as abordadas nos tópicos anteriores desse ensaio, como a dinâmica da sustentação de um confronto, o processo de mobilização de recursos e as mudanças na ação coletiva, por exemplo, são essenciais para pensar a dimensão estratégica e relacional na ação coletiva.

Entretanto, como já sinalizado anteriormente, gostaríamos de apontar duas contribuições específicas de Sidney Tarrow não tão bem desenvolvidas na literatura especializada que se debruçou nos trabalhos do autor, mas que têm pertinência e consequências consideráveis para a teoria social e políticas, bem como consequências metodológicas para os estudos do campo. A primeira delas está relacionada com o enfoque na dimensão política e nos fluxos e refluxos do confronto político, demarcando um importante rompimento com a teoria da mobilização de recursos.

Encabeçada pela Teoria da Mobilização de Recursos (TMR), predominava no campo de pesquisa sobre ação coletiva nos Estados Unidos a análise dos benefícios e custos necessários para o ato de agir (McCARTHY; ZALD, 1977). Sob destacada influência da Teoria da Escolha Racional (TER), na TMR ganha destaque o cálculo racional dos recursos materiais e imateriais relacionados com o surgimento dos movimentos, os quais funcionariam como empresas que cooperam e competem entre si, em busca de bens políticos e novos membros (ALONSO, 2009).

Estud. sociol. Araraquara v.24 n.46 p.305-319 jan.-jun. 2019 
A ruptura de Tarrow (2009) com a tradição da TMR ocorre sobretudo no deslocamento da centralidade da análise sobre recursos, para um enfoque nos fluxos e refluxos da luta política. Apesar de não desconsiderar a importância dos recursos para o estímulo à ação coletiva, como abordamos nos tópicos anteriores, para ele o confronto político e a formação de movimentos sociais dependem de oportunidades e restrições que surgem a partir da dinâmica da política, possibilitando que indivíduos com acesso limitado a recursos sejam estimulados a participar de uma contenda. Nesse entendimento, o cálculo racional de custos e benefícios da participação seria deficiente para a compreensão do confronto político por ignorar a dinâmica de oportunidades e restrições que surgem a partir dos fluxos da luta política em um determinado local.

Ao enfatizar os fluxos do confronto, o autor rechaça o utilitarismo e o individualismo metodológico, centrando a análise na dimensão política da interação entre movimentos e autoridades. Como consequência, para se pesquisar movimentos sociais ou confronto político a partir do pensamento tarrowniano é necessário levar em conta a historicidade: a história é construída a partir de atores que agem, gerando novas oportunidades de ação em uma reação em cadeia, a qual não é possível controlar seus resultados. Em suma, o confronto político deve ser analisado considerando suas constantes transformações, a partir de repertórios em permanente mudança em um contexto onde oportunidades geram novas oportunidades.

O segundo elemento que trataremos aqui está relacionado com as divergências do autor em relação à natureza dos movimentos sociais. Na tradição da Teoria dos Novos Movimentos Sociais, sobretudo em Melucci (1989, p.52), os movimentos são comumente estudados como "sistemas de ação operando em um campo sistêmico", não existindo como experiências empíricas exatas, mas sim como conceitos analíticos. Nessa perspectiva "um movimento social é um objeto construído pela análise e não corresponde as formas empíricas de ação" (MELUCCI, 2001, p.28).

Contudo, Tarrow (2009) se distancia dessa perspectiva por não analisar os movimentos sociais a partir de um conceito analítico exterior à experiência. Por considerar os movimentos sociais como invenções históricas, o autor se debruça no processo de formação dos movimentos e nas experiências empíricas ocorridas. Por isso, em vez de trabalhar com um conceito preciso de movimentos sociais que oriente a análise e defina com exatidão quais experiências podem ser consideradas como tal, ele opta por uma definição ampla tratando-o como sequências de confronto político com a capacidade de manter desafios sustentados contra autoridades.

Por não definir um conceito apriorístico que possa enquadrar a análise sobre o tema, torna-se necessário verificar as diversas experiências de sustentação de confronto político e a partir disso traçar suas propriedades empíricas. Nessa perspectiva, para aplicar a análise desenvolvida por Tarrow, não é possível desvencilhar movimentos sociais de confronto político. 
Os movimentos sociais, como resultados históricos do fluxo e refluxo da luta política, só podem ser compreendidos, portanto, a partir da análise do conflito mais amplo o qual se inserem. Sem a devida atenção à dinâmica do confronto, os elementos essenciais para a análise se esvairão entre os dedos do pesquisador. Dessa maneira, análises que forçam conceitos analíticos ao objeto e que o isolam do campo relacional no qual está inserido, se distanciam dos postulados defendidos pelo autor.

Para dar conta das escolhas metodológicas apresentadas, ao longo de inúmeros estudos sobre o confronto político e movimentos sociais o autor em questão opta pela análise sociohistórica e pelo método da comparação (TARROW, 1989, MEYER; TARROW,1998). As mudanças macro-históricas com impacto nas estruturas de oportunidades são levadas em conta, enquanto a partir de extensa comparação o confronto político é desvelado. A investigação cuidadosa do confronto e do seu desenrolar, possibilitam ao autor interessantes contribuições relacionadas com o diálogo entre teoria e história.

Alonso e Botelho (2012) pontuam que a partir da conexão entre teoria e história, na perspectiva que o autor leva em conta tanto a capacidade de agência e criatividade dos atores, quanto os constrangimentos políticos e históricos, ele logra superar a dicotomia ação/estrutura.

\section{Conclusão}

Este ensaio teve como intuito apresentar alguns conceitos chaves do trabalho Sidney Tarrow. Ao longo de uma carreira profícua, este autor, tem apontado interessantes caminhos para os estudos sobre o confronto político contribuindo para as ciências sociais como um todo. Reforço, que suas contribuições relacionadas com a noção de uma dimensão política do confronto e com os fluxos da luta política têm possibilitado um interessante desenvolvimento de um campo renovado que busca investigar a temática sem cair no utilitarismo ou em noções restritas de movimento social.

Em diálogo com novas teorias da Sociologia e da Ciência Política, esse campo tem apresentado uma vigorosa produção ao mapear e analisar o tema em questão, além de discutir noções chaves das teorias sociais e política. Dessa maneira, o pensamento desse destacado autor tem sido constantemente revisitado, tendo em vista a inovação de alguns de seus postulados.

Enfim, a partir de uma discussão cuidadosa sobre atores em uma contenda política Sidney Tarrow apresenta conceitos essenciais para uma análise que leve em conta o processo dinâmico de disputa no qual se inserem os movimentos sociais, sobretudo, para pesquisas que pretendem investigar a interação entre desafiantes e autoridades. 


\section{SOCIAL MOVEMENTS AND POLITICAL CONFRONTATION: NOTES ON THE THOUGHT OF SidNey TARROW}

ABSTRACT: This essay proposes to discuss the main assumptions of Sidney Tarrow's thought, as well as its consequent contribution to the field which is inserted from three central elements: a) social movements as expression of the political confrontation; b) the outbreak of social movements; c) dynamics and elements of the political struggle. In this sense, the author's focus on the political dimension and the flow of political confrontation have enabled the development of a field which approaches social movements as historical inventions resulting from the dynamics of political confrontation, distancing itself from systemic conceptual approaches.

KEYWORDS: Social Movements. Sidney Tarrow. Political Confrontation

\section{MOVIMIENTOS SOCIALES Y CONFRONTACIÓN POLÍTICA: apUntes SOBRE El PENSAMIENTO De Sidney TARROW}

RESUMEN: Este ensayo tiene como objetivo discutir los principales supuestos del pensamiento de Sidney Tarrow, así como su consiguiente contribución al campo, que se inserta a partir de tres elementos centrales: a) movimientos sociales como expresión del enfrentamiento político; b) surgimiento de los movimientos sociales; c) dinámica y elementos de la lucha política. En ese sentido, el enfoque del autor en la dimensión política y en los flujos y reflujos del enfrentamiento político posibilitó el desarrollo de un campo que aborda a los movimientos sociales como invenciones históricas resultantes de la dinámica del enfrentamiento político, distanciándose de abordajes conceptuales sistémicos.

PALABRAS CLAVE: Movimientos sociales. Sidney Tarrow. Conflicto politico.

\section{REFERÊNCIAS}

ALONSO, Angela. As teorias dos movimentos sociais: um balanço de debate. Lua Nova, São Paulo, 76: 49-86, 2009. Disponível em: <http://www.scielo.br/pdf/ln/n76/n76a03.pdf.>. Acessado em: 05 de Dezembro de 2017

ALONSO, Angela; COSTA, V. e MACIEL, D. Identidade e estratégia na formação do movimento brasileiro. Novos Estudos, n. 79, novembro, 2007. 


\section{Diego Matheus Oliveira de Menezes}

ALONSO, Angela; BOTELHO, André. Repertórios de ação coletivo e confrontos político: entrevista com Sidney Tarrow. Sociologia \& Antropologia. v.02: p.11-19, 2012. Disponível em: <http://revistappgsa.ifcs.ufrj.br/wp-content/uploads/2015/05/2-ano2v3_artigo_angelaalonso_andre-botelho.pdf.>. Acessado em: 03 de Dezembro de 2017

McADAM, Doug. Conceptual origins, current problems, future directions. In: McADAM, Doug; McCARTHY, D. John \& ZALD, N. Mayer. (orgs.). Comparative Perspectives on Social Movements. Political Opportunities, Mobilizing Structure, and Cultural Framings. Cambridge University Press. 2006

McADAM, Doug; TARROW, Sidney; TILLY, Charles. Para mapear o confronto político. Lua Nova, São Paulo, p.11-48, 2009. Disponível em: <http://www.scielo.br/pdf/ln/n76/ n76a02.pdf. >. Acessado em: 11 jun. 2019.

McADAM, Doug; TARROW, Sidney; TILLY, Charles. La dinámica de la contienda. Hacer Editorial. 2005.

McCARTHY, J. D.; ZALD, M. N. Resource mobilization and social movements: a partial theory. The American Journal of Sociology, vol. 82, nº 6, May 1977, p.1212-1241. Disponível em: <https:/campus.fsu.edu/bbcswebdav/institution/academic/social_sciences/ sociology/Reading\%20Lists/Stratification \%20\%28Politics \%20and\%20Social\%20 Movements\%29\%20Copies\%20of\%20Articles\%20from\%202009/McCarthy-AJS-1977. pdf. $>$. Acessado em: 22 de Janeiro de 2018

MELUCCI, Alberto. A invenção do presente: movimentos sociais nas sociedades complexas. Petrópolis, Rio de Janeiro. Vozes, 2001.

MELUCCI, Alberto. Um objetivo para os movimentos sociais. Lua Nova. São Paulo, p. 50-66, 1989

MEYER, David.; TARROW, Sidney. (orgs.). The social movement society: contentions politics for a new century. Lanham, MA: Rowman\& Littlefield. 1998

TARROW, Sidney. Poder em Movimento: movimentos sociais e confronto político, Petrópolis: Ed. Vozes, 2009.

TARROW, Sidney. Democracy and disorder: protest and politics in Italy, 1965- 1975. Oxford e New York: Oxford University Press, 1989.

GIUGNI, Marco; McADAM, Doug; TILLY, Charles (eds.). From contention to democracy. Lanham: Rowman \& Littlefield, 1998.

TILLY, Charles; Popular contention in Britain, 1758-1834. Cambridge, Mass.: Harvard University Press. 1995. 
TILLY, Charles; TARROW, Sidney. Contentious politics. Boudler: Paradigm Publisher, Colorado. 2007.

SNOW, David; BENFORD, Robert. Master frames and cycles of protest. In: MORRIS, A. D.; MUELLER, C. M. (eds.). Frontiers in social movement theory. New Haven London: Yale University Press, 1992. Disponível em: <https://www.researchgate.net/ publication/246773271_Master_Frames_and_Cycles_of_Protest. $>$. Acessado em:10 de Janeiro de 2018.

Recebido em 10/02/2018.

Aprovado em 15/02/2019. 
